[From SCIENCE Gossip.] NOTE ON MELICERTA RINGENS

BY W. B. DALUWGaER, LL.D., T.R.B., F.R.M.8., ETO

This small and beautiful denizen of our ponds has become so familiar an object to the amateur, and has

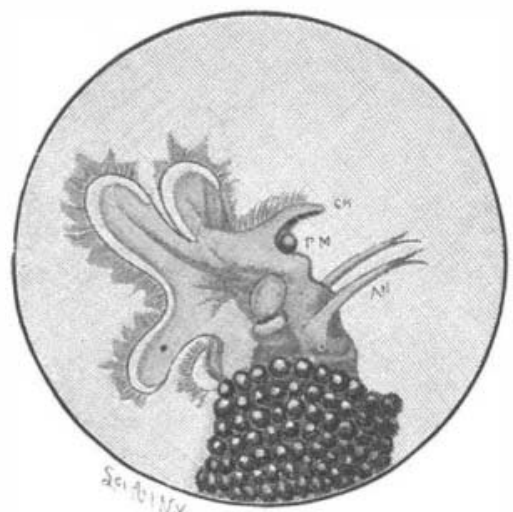
so long command ed the interest and close observation of the student, that it may fairly be supposof prolonged and systematic study could tell us more concerning it than from so many contributors is now
known. Apart known. Apart ful results ob-

Fra. 2.-M. rngens, showing the ciliated lobes, fained by the in-
the chin, CH, the peilet in its mould, P M, and taind the chin, CH, the peilet in its mould, PM, and taight and patient
antenna, A N. Copied by Dr. Dallinger from sight
Ggure by Dr. Hadion.
rese a r c hes of Gosse (') confirned and enriched by scores of subsequent observers, it may be doubted if anything nore thorough could be done than that by Mr. Charles Cubitt $\left(^{(}\right)$and Judge which its unexpected and rapid change of position Bedwell ( ${ }^{3}$ ), on the characteristic and really wonderful causes you, the act, like a conjuring trick, is over, and features of this rotifer, all of which has been carefully considered and analyzed by the chief authority on this subject, Dr. C. T. Hudson ( $\left.{ }^{4}\right)$.

Nor is there any claim in this note for the addition of any fact to our previous knowledge; it is simply a demonstration of the manner in which a detail familiarly known to be constantly carried out is accomplished.

No greater perplexity presented itself to the earlier microscopists in the study of this and sinilar forms than the extreme limits of space involved in the use of objectives of considerable magnifying power.

For many years the habits and activities of Melicerta ringens have afforded me the keenest pleasure and interest, and to many of these I have applied with admirable results the advantageous properties of the apochromatic system; and there is one point in which it has tem; and there is one point

In the summers of 1893 and 1894 I was fortunate enough to come upon an exceedingly abundant supply of these organisms, and they were not only very plentiful, but extremely vigorous; moreover, many of them were evidently of greater age than those I had usually seen. This was manifest in the great comparative length of some of their tubes, and the remarkably graduated sizes the pellets presented from the base to the top edge; also in sented from the base to the top the confluence or "weathering" of these in the lowe algæ, diatoms, conferva, and other things upon the tubes.

An average one drawn from life is shown in Fig. 1. The intense and rapid action of the cilia arrested even an eye familiar with the object; and the lobesassumed a great variety of soft and beautiful curves, not unusual but never so frequently seen before. A very common one of these is shown in the illustration.

It is not too wuch to assume that the readers of this journal are familiar with all the actions of this beautiful rotifer as a brick maker and a tube builder. It is familiar to all that by the cilia about the edge and upon the bosom of her petal-like lobes she obtains a vertical stream of particles which are with wonderful delicacy separated into material serving for food and material serving for the manufacture of the pellets, which are afterward used as "bricks" to build her tube in a succession of rings. We may perhaps be pardoned none the less for borrowing a figure from Dr. Hudson (Fig. 2) which shows the ciliated lobes, the "chin" (CH), the pellet in its mould or cup (PM), and

"chin" (CH), the
the antennæ (AN).

Mr. P. H. Gosse says: "Below the larger petals (that is, on the ventral side) there is a projecting an-
gular chin (CH, Fig. 2) which is ciliated; and immediately below this is the little cup-like organ,

small hemispherical cavity. . . . On my mixing carmine with the water the course of the ciliary current was readily traced, and formed a fine spectacle. The particles are hurled round the margin of the disk until they pass off in front through a great sinus between the larger petals. . . . If the atoms befew we see them swiftly glide along the facial surface, folwe see them swiftly glide along the facial surface, fol
lowing the irregularities of outline with beautiful precision, dash round the projecting chin (CH, Fig. 2) like a fleet of boats doubling a bold headland, and lodge themselves one after another in the little cup-shaped receptacle beneath (PM, Fig. 2). • . . The contents of the cup are whirled round with great rapidity" ( 8 ), is built. Now the fact that these pellets or "bricks" having seen the brick produced, says : "I now watched other pellet. I This process I saw repeated many times in succession, until a goodly array of pellets were A $:$. but very irregularly" $\left({ }^{\circ}\right)$

Again, in regard to a young melicertan, "A pellet was quickly formed and instantly deposited at the and industry, so that in a few minutes a row of pellets were see

Again, the pellet having been formed, "Suddenly now we see the animal bend itself forward, till the cupis brought into contact with the upper edge of the
case, it remains so bent for an instant, and then as uickly resumes its upright position. The cup, howver, is now empty : for the consolidated pellet.

has been left on the edge of the case" ( 8 ).

In the same way that most careful and acute observer, Judge Bedwell, tells us in regard to the deosit of the "'srick," that "it does it so quickly, that which its unexpected and rapid change of position

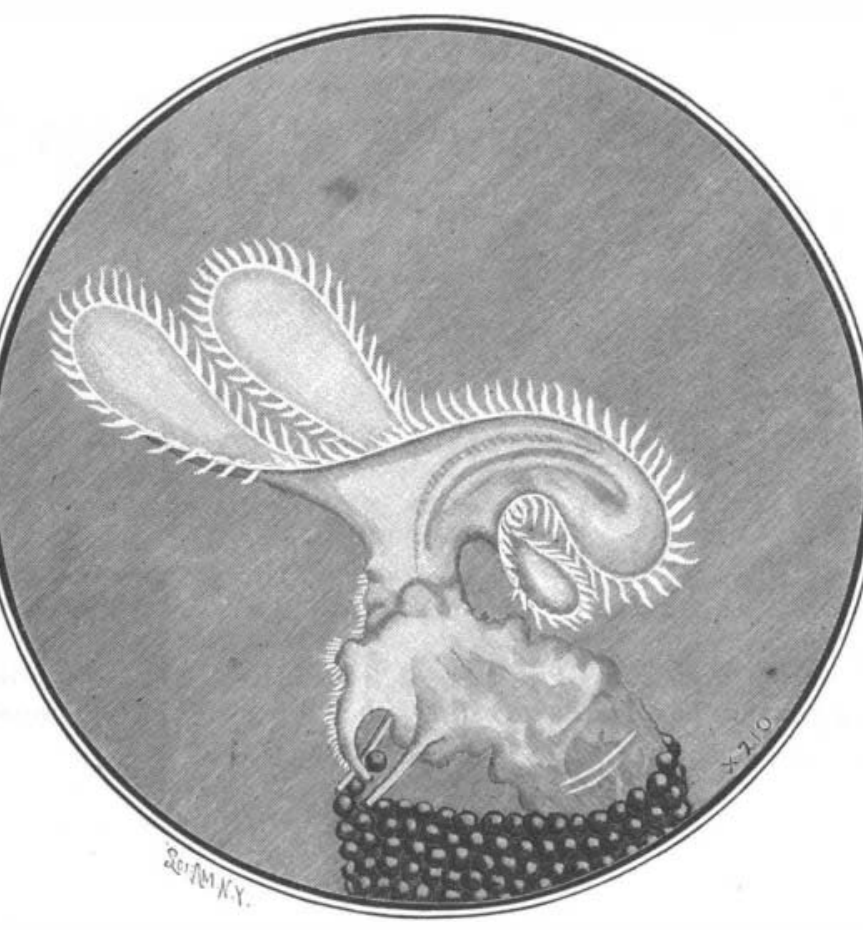

placing pellet,
Dr. Dallinger.

the animal is in its old position again, with an empty ellet organ hard at work at a new brick" $(\bullet)$

It will of course be clear, and is fully known to every observer, that it must be a matter of difficulty to see distinctly what are the details of this brickla $;$ ing, effected, as it is, so rapidly. The prime elements of success are sharpness of definition, with sufficient magnification, and ample room for the activities of the rotifer.

With plenty of vigorous specimens in full activity and by happy incidence, one well placed and building, taking a $24.0 \mathrm{~mm}$. objective, we nay commence with the initial magnification of the lens $(10.5$ times), and we may go on to 250 or nore diameters without change nd repeated observation, we may at last observe all the simple details of the placing of the brict.

Judge Bedwell made the observation that a small pimple-like protuberance armed with setæ and lying etween two hooks, on the opposite side of the cup in which the brick is made, possibly determines the place in which the brick is to be deposited; for "when the pellet is ready the animal turns round and deposits it t the spot with which this pimple . . . was in conact at the moment before the animal began to urn" $\left({ }^{10}\right)$.

This is undoubtedly true; in the cases observed by him it may have been always true, but in the many observations made through two summers I found that it was never so with the first brick of a new ring, but with the exception of three instances was aiways the ase with every other pellet of the ring. What hap-
pened is shown in Fig. 3. The brick was ready, being always formed in from three to four minutes, then the rotifer $t$ wisted swiftly round about half the circumference of her tube, pressed the side of her body against the side of the tube she had just turned herself from arched her body over, laid her antennæ parallel wit each other and near enough to each other to form a sort of double rail or frame, down which the pellet could roll or slide, and guiding it to the exact spot to "chin" she pressed it into position, much as, with a f focus or disturbance of the object : and by patience

were deposited in rings, constituting the familiar tube, finger, we may press an electric knob, and then inis a mere commonplace of the natural history of minute stantly rose, mostly turned rapidly to its former posilife. In his first and most original paper, Mr. Gosse, tion, and again proceeded to the construction ct an-

the animal with eager expectation, and presently had When we remember that the dot of an " $i$ " in this the satisfaction of seeing it bend forward its head, as type will probably more than represent the superficial

I had expected, and aftera second or tworaiseit again, area occupied by the organism, all these refinements f operation must surely awake interest in the mind, nd cause the least thoughtiul to perceive that size is merely a finite mental concept and in no way affect the perfection of the adaptations with which a living organism is endowed.

EFERENCES TO WORKS QDOTED IN THIS ARTICLF (1) Trans. Micros. Soc., vol. iii, 1852, p. 58 ; Quart. Journ. Micros. Soc., vol. i, 1853, p. 71 ; Pop. Sci. Rev.,

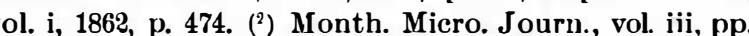
40-1 : ibid., vol. v, 1871, p. 205 : ibid., vo!. viii, 1872 , p. J. R. M. Soc., vol. i, p. 245. (4) J. R. M. Soc., vol. ii, 879, p. 6: "The Rotifer," by C. T. Hudson and P. H. Gosse, two vols., 1886. (ब) Tenby, pp. 314-315. (ब) Trans. Micro. Soc., vol. iii, 1852, p. 62. (7) Quart. Journ. Micros. Sci., vol. i, 1853, p. 75. (8) Popular vol. xviii, 1877, p. 221. (10) Month. Micros. Journ., vol xviii, 1877, p. 221 .

Tho Vesicating Colnstituent of Croton oil.

In a conmunication made to the Royal Society. Mr. ndham R. Dunstan, M.A., F.R.S., and Miss L. F Boole, Lecturer on Chemistry in the London School of Medicine for Women, record the re sults of an experimental inquiry into the nature of the vesicating constituent of croton oil. According to the research of Buchheim, and more recently of Kobert and Hirscheydt, the vesicating action of croton oil is due to an acid closely allied to oleic acid, which hus been civen the naile of crotonoleic acid, and which is now prepared for medical purposes on a larg scalein Germany. $y$, in the formation first of barium crotonoleate, and the subsequent decomposition of this with dilute sulphuric acid, and extraction of the liberated crotonoleic acid as a viscid oil with ether. By a process of fractional precipitation, using lead salts, the above investigators were able to separate from this so-called crotonoleic acid a large proportion of inactive oily acids, till at last they were successful in obtaining by a series of operatic holic extraction and separation by means of lead oxide were made use of a resinous substance having extraordinary power as a vesicant. The composition of this resin is $e x-$ cant. The composition of this resin is exAll attempts to crystallize or to obtain ory talline derivatives failed. It is a hard, pale yeliow, brittle resin. nearly insoluble in water, light petroleum, and benzene. but readily dis solved in alcohol, ether, and chloroform. In regard to its constitution it is concluded that the vesicating constituent of croton uil is a lactone or an anbydride of complicated structure.

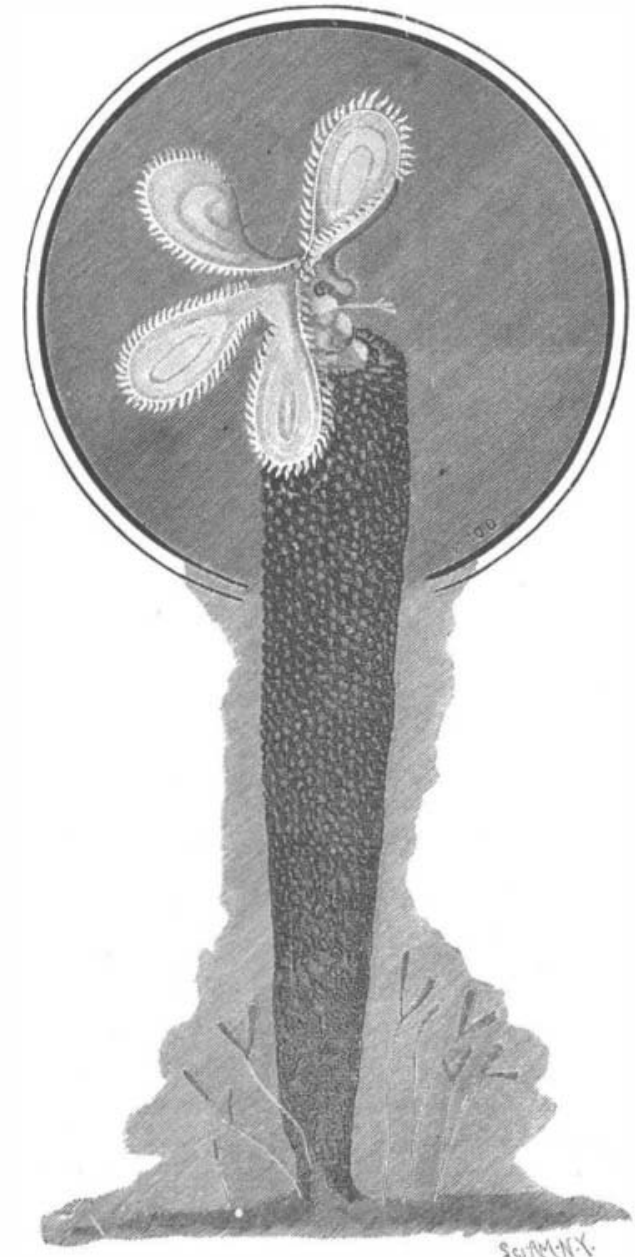

Fro. 1.-Melicerta rngens, $\times 100$. Drawn from nature by 
Photographing the Heavenly Bodtes by an

We first of all desire to disabuse the mind of the average photographer that, in order to practice celestial photography, one must necessarily be possessed of very costly instruments, such as elaborate and large astronomical telescopes, and equally elaborate equatorial stands, with clockwork for driving the same, which are undoubtedly necessary in the observatory in which it is desirable to get out of the heavens all that they contain. But our desire is at present to point out how a vast amount of real pleasure is to be
obtained by practicing celestial photography with obtained by practicing celestial photography with
such a camera, lens, and stand as all photographers are supposed to possess.

The dimensions of camera in which we have found the balance of advantages to reside is that for 5 by 4 plates, the lens used in conjunction with it being a portrait one, which works with great rapidity of action, covering the above named plate without any diaphragm. When we state it to be the well known No. 2B of Dallmeyer, our readers will at once realize
that its aperture is two and three-quarters inches and that its aperture is
its intensity great.

From our experiments on the moon with this lens, we find the concentration of light so great as to permit of an instantaneous exposure being given. As every one knows, the moon sails across the heavens with an apparent quick motion, a motion that will be more readily appreciated if it be examined by a telescope fixed on a stand. With a lens such as that just mentioned, and on a clear night, an exposure of such short duration may be given as to enable a well exposed neyative to be secured-one which, when examined under a compound microscope, shall show, in a well marked manner, ail the salient features of our satellite. This caunot be obtained if the exposure be prolonged, in consequence of the lunar motion, owing to which any departure from instantaneity will give a elliptical instead of a circular shape.

It need scarcely be remarked that by employing a lens of longer focus than the one mentioned a larger image will be obtained; but, unless the angular aperture of the objective be equal to the shorter one, this will be at the expense of rapidity, unless, of course the camera be mounted on an equatorial stand, when the expos

We have spoken of a high class equatorial stand as being expensive. So it is for observatory work, but for ordinary photography it need not be so. It is quite possible to construct one of a somewhat is quite possible to construct one of a somewhat
rude appearance for a few shillings, but which will be capable of doing good work. We will describe one of this class, which we had made some time since. The legs are hinged to a very strong table, on which are two spirit levels standing at right angles to each other. Raised up at a slope from the table is a strong tube, which is fixed very securely. The angle at which it is raised must be equal to the latitude of the place where operations are to be performed. This can easily be ascertained from any good map, in which the lines of latitudes will be found given at the right and left sides. For example : At Kirkwall it would be found to be $58^{\circ} 59^{\prime}$; at Edinburgh, $39^{\circ} 56^{\prime}$ at London, $50^{\circ} 31^{\prime}$, and so on. The tube, when thus erected, forms the polar axis, for it must always point to the pole star, and it must be supported in a steady position by a strong strut. We may here note north, but it is quite near enough to serve our present purpose.

A rod, which carries the table for the canera, is fitted to pass smoothly into the upright tube spoken of, so as to allow the camera to revolve. The table on which the camera sits, and to which it is attached by a thumbscrew, is folded, and is hinged at the front, so
as to be capable of being directed up or down and pointed to any object in the heavens. When this is done, a pinching screw secures the hinged part, to
which the camera is attached, at the angle found necessary.

No other adjustment is needed for that particular object, which may be the moon, a constellation, or planet. By rotating the camera slowly on its axis, a celestial body may be kept motionless on the sensitive
plate for a protracted period. When the lower end of plate for a protracted period. When the lower end of
the polar axis terminates in a fine point fitting into a socket, and friction is thus diminished, it is surprising with what ease a heavy camera is made to revolve even by such a flimsy motor as one of those round lever clocks
shillings.

To give the proper motion to the camera is a matter of the utmost importance. One way in which we had an equatorial camera stand made, and by which the camera could be made to rotate by hand with a wonderful degree of exactness for a brief period, was by
having attached to, and projecting froln, its side a segment of a finely toothed wheel, into which geared an "endless screw" terminating in a handle, one revolu tion of which caused the segment of the wheel to re volve to the extent of one tooth, the camera being, of course, carried forward in a corresponding degree. It dies been urged and are so many newspaper remeis important that a powerful little telescope be mounted
on the same stand as the camera. In the eyepiece of
but the majority are worthless. In fact, rather than on the same stand as the camera. In the eyepiece of
this must be fixed cross hairs, and the eye and hand
put faith in half of those which have been published, of the operator must be so tutored that, when the it were better to rely on the recipe which T. A. Janimage of, say, the moon is seen on the cross hairs, it vier gives in his charming article on 'Mexican Supermust be kept in exactly the same spot by the rotating stitions and Folk-lore,' published in a recent number of the handle of the endless screw referred to.

A very pretty negative of a constellation, suitable A very pretty negative of a constellation, suitable
or employing as a lantern slide, may be taken instantaneously by the portrait lens already alluded to, or one possessing similar characteristics. In this case a stand, although convenient, is not an absolute neces-
sity. The first thing one will notice is that, whereas with an instantaneous exposure the principal stars of a constellation will only appear in the negative, yet, $i$ the exposure be prolonged, the number of those pho tographed will be increased; while, by prolonging the exposure still more, stars so remote and weak as to be ncapable of being seen by the eye at all will be visible in the photograph. This, as we have for-
merly pointed out, is the principle underlying the new astronomy.

When the subject is wanted to be magnified to a considerable extent, a tele-photo lens will be found to be an improven.
lens. $-\mathrm{Br}$. Jour.

\section{CROTON BUGS INJURIOUS TO OFFICE PAPERS.} ANSWER BY PROF. c. v. RILEY.

The somewhat mutilated and compressed specimens ent for identification by Mr. H. C. Stoddard, of Vilwell known Croton bug (Ectobia germanica). It is at this stage they look sufficiently unlike the adult bugs, being of a pale color, with the thighs of the legs more swollen relatively. This is one of the cock roaches which is most frequently found in offices, li braries, etc., where it is well known to do very considrable damage. It is a European species, and derive
its common name in this country from the fact that

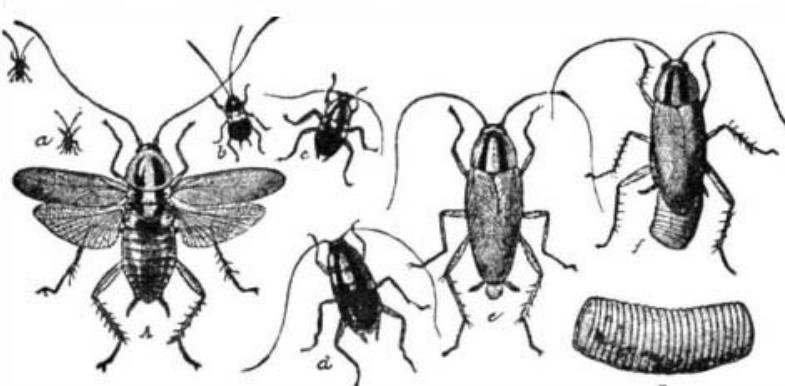

The Croton Bug, or German Cockroach (Phyllodromia germanica); $a$, first
stage; b, second stage; $c$, third stage; $d$, fourth stage; $e$, adult; $f$, adult stage; b, second stage; $c$, third stage; $d$, fourth stage; e, adult; $f$, adolt
female with egg case; $g$, egg case, enlarged; $h$, adult with wings spread. female with egg case; g, egg case, enlarged;
All natural size, except g. (After Riley.)

it first made its appearance in numbers about the time of the completion of the Croton system of wate
works in New York City. The insect is fond of moist places, and is often carried by pressure through water
pipes without injury. It is very prolific, and, owing to its small size, can hide and breed in drawers and in varying somewhat, is of a rather light brown, with two darker longitudinal stripes on the thorax. Like other cockroaches, it is nearly
fers animal to vegetable matter.

In the city of Washington and further south, the croton bug eats everything that contains paste and is particularly injurious to books which are bound in cloth. on account of the large amount of paste used in making the cloth covers. But wall paper, photo-
graphs, and all sorts of staticnery naterial suffer from its injuries. I have given an account (Insect Life, Vol. I, p. 67) of the severe injury done to import ant files in the Treasury Department and in the United States Coast and Geodetic Survey, where the! insects
had become an intolerable nuisance by eating off the surface and particularly the red and blue paint fron drawings of important maps. From this article I quote the following as to remedies :

"Without condemning other useful measures or rem dies like borax, I would repeat here what I have at ready urged in these columris, viz., that in the free and persistent use of California buhach, or some other
fresh and reliable brand of Pyrethrum or Persian insect powder, we have the most satisfactory means dealing with this and the other roaches mentioned.

"Just before nightfall go into the infested room nd puff it into all crevices, under baseboards, into the drawers and cracks of old furniture-in fact wherever there is a crack--and in the morning the loor will be covered with dead and dying or demorlized and paralyzed roaches. which may be easily cleanliness and persistency in these methods, the pest cleanliness and persistency in these methods, the pest
may be substantially driven out of a house, and should never be allowed to get full possession by immigrant rom without. \begin{tabular}{l|l} 
"For no other insect have so many quack reme- & with 120 volts.
\end{tabular} lamps. not at all surprising that he did not recognize them, a places, and is often carried by pressure through water racks and crevices where the larger American cock-
roaches are rarely found. At maturity its color, while Scribner's Magazine, March, 1889 ,
50 ), as current anong the Mexicans:

"To Get Rid of Cockroaches. - Catch three and put them in a bottle, and so carry them to where wo roads cross. Here hold the bottle upside down, and as they fall out repeat aloud three credos.
Then all the cockroaches in the house from which these three came will go away!"

Cells.
The spectacle of energy and vigorous growth which the garden and field afford at the present time should ill every thoughtful mind with reverent wonder. Man when he projects some complicated building filled with apparatus and conveniences for varied purposes, plans numerable workmen, all skilled in their various in partments, fashions and shapes the needful materials, and by building the fabric up piece by piece, finally triumphs in his completed work. If, however, he triumphs in his completed work. If, however, he
wants to duplicate or enlarge it, precisely the same process has to be gone through again, and the first work only aids him as a pattern.

In Nature, however, we find the most complicated fabrics apparently making themselves; and having one of these in our possession, we may, as it were, pull a brick out of the factory wall, stick it in the middle of and spreading around until we begin to see the plan of another factory developing; everything be adjusted to a nicety as the performance goes on, until finally all is complete and in full working order. Can anything be more marvelous than this ? and yet it is going on all the time, and if any reader fails to grasp the fact,
let him get a mirror and see such a factory in himself. These wonderful bricks are the cells; and of course in man himself the marvel is the greater that some of the cells which contribute to build him up, i. e., his brain cells, are the fathers of the inorganic fabrics which dot the world with cities and towns, and seam it all over with the beneficent mycelium of rail and road which at once engenders and fosters their extension.

In the vegetable kingdom this power of self-construction in the cell is easily studied in some of its lower form by means of a microscope; some of the translucent water weeds especially display very clearly the delicate network of cells which constitute their comparatively simple structure. Valisneria spiralis does so to perfection, and the circulation of the sap from cell to cell is shown very clearly. A very simple object, showing not only how the cells multiply, but also in a small degree that inscrutable wonder of building to plan, is the prothallus of a fern, the little green scale produced by the spore. A periodical examination of one of these rom the time it is a tiny dot up to that of the full-size scale, will show distinctly all the stages of self-shaping, and also the differentiation into root hairs, and the re productive organs, which may be regarded as the machinery above alluded to. A few spores scattered on from time to time without easily handled and examined ple manifestation it becomes easier to carry the mind to the more complex cases where plants not merely build themselves up into stems, leaves, and charming fowers, but more marvelous yet, constitute themselve ubtile chemical laboratories in addition, in which the deadliest poisons, beneficent medicines, or nutritiou food and stimulants are all alike formed from the sam zoil constituents by Nature's own alcheny. The self same family, indeed, may embrace both extremes, the deadly nightshade and the tomato to wit, or, more wonderful yet, one and the same fruit, such as a peach may yield a store of delicious food in its flesh, whil hiding the deadliest of poisons, prussic acid itself, in the kernel. Truly, when we consider these things the
spectacle of a plant in full growth is one of overwhelming interest, as active evidence of the reative power of which we know so little though we see so much.The Gardeners' Magazine.

\section{The Torpedo Fish.}

At the last meeting of the Academy of Science, Professor D'Arsonval, of the College de France, read an interesting paper on a series of experiments which he A lately with the torpedo fish.

A fish 30 cent. in diameter he found could give out a shock of twenty volts. Professor D'Arsonval applied some small electric lamps to the fish and they were lit by the discharge from its body. In some instances discharge was so powerful as to carbonize the

The electric current generated by the torpedo fish is sufficiently powerful to kill small fish coming in contact
with it. The electric discharge can even go as high as 